\author{
Alireza Shamsi', Reyhaneh Sadat Tohidi ${ }^{2}$, Maryam Shamekhi', Hamed Amirifard², \\ Alireza Ansarimoghadam ${ }^{3}$ \\ ${ }^{1}$ School of Medicine, Shahid Beheshti University of Medical Sciences, Tehran, Iran \\ 2School of Medicine, Zahedan University of Medical Sciences, Zahedan, Iran \\ ${ }^{3}$ Zahedan University of Medical Sciences, Zahedan, Iran
}

\title{
The relationship between personality characteristics and the quality of life in patients with epilepsy
}

\begin{abstract}
Introduction: Identification of effective factors in the quality of life (QOL) of patients with epilepsy is important in improving their quality of life. Regarding this, the present study aimed to investigate the relationship between personality characteristics and QOL in patients with epilepsy.

Material and methods: This cross-sectional study was conducted on 100 epileptic patients referred to Neurology Clinic of Ali-ibn Abi Talib Hospital in Zahedan, Iran in 2015. The NEO Personality Inventory (NEO-PI) and Short Form Health Survey (SF-12) questionnaires were used to determine the personality characteristics and QOL scores, respectively. Results: The mean of QOL score was 28.94 4 4.58. Age, gender, marital status, education level, and duration of epilepsy had no significant correlation with the QOL. The QOL showed a negative correlation with openness to experience and neuroticism. However, this variable had a direct correlation with conscientiousness, agreeableness, and extraversion. There was a significant relationship between the predictor variables (extraversion and neuroticism) and the criterion variable (QOL). Therefore, extraversion and neuroticism can be considered as the predictors of the QOL.

Conclusions: The extraversion and neuroticism seem to be two predictors of the $\mathrm{QOL}$ in the epileptic patients. Accordingly, whereas the patients with high levels of neuroticism had low QOL, this value was higher in those with high levels of extraversion.
\end{abstract}

Psychiatry 2020; 17, 2: 66-70

Key words: epilepsy, quality of life, personality, neo personality inventory

\section{Introduction}

A seizure occurs as a result of a sudden surge and abnormal electrical activity in the brain, which leads to physical manifestations or changes in behavior. Epilepsy is one of the most common neurological diseases, which is characterized by repeated seizures and can affect people at any age [1]. The incidence of epilepsy in general population is 45 per 100,000 people and its prevalence is $0.5 \%$. Furthermore, the lifetime risk of epilepsy is about $3 \%$ [2] In Iran, more than 30,000 patients are annually diagnosed with epilepsy $[3,4]$. The incidence of psychiatric

Adres do korespondencji:

Alireza Shamsi

School of Medicine

Shahid Beheshti University

of Medical Sciences, Tehran, Iran

e-mail: ar.shamsi@sbmu.ac.i problems such as depression, anxiety, and psychosis is highly prevalent among epileptic patients. Accordingly, more than a quarter of this population has a history of psychological problems and more than $10 \%$ of the patients admitted to the psychiatric hospitals suffer from epilepsy [5]. Some types of epilepsy are associated with greater psychological defects. Co-morbid disorders of epilepsy also affect the quality of life (QOL) [6].

Health-related QOL, a multi-dimensional concept, is considered as the assessment and perceptions of the people about the effect of the defects, diseases, and deprivations in their daily functions and social opportunities. In other words, this concept covers the areas related to physical, mental, emotional, and social functioning $[6,7]$.

The concept of QOL is defined by both subjective and objective criteria. The subjective criterion denotes the 
individual's judgment on his living conditions, which is considered as feelings of satisfaction, well-being, and happiness. There are many different definitions to the QOL, which make this concept difficult to quantify. Furthermore, according to the literature, there are many factors affecting the QOL, such as financial status, religion, and mental health [8].

Personality characteristics play an important role in response to the physical illness [9]. The relationship between personality characteristics and QOL was investigated in several studies $[10,11]$. The four main areas of the QOL in the epileptic patients are the mental, physical, and cognitive health problems as well as stress, which lead to lower QOL in the epileptic patients, compared to the healthy people [12].

With this background in mind, compatibility with epilepsy and its consequences is vital.

In Iran, the epileptic patients constitute a relatively large population; therefore, improving the $\mathrm{QOL}$ in these patients is a matter of significant importance. Regarding this and given the importance of the relationship between personality characteristics and QOL [13], this study aimed to investigate the relationship between personality characteristics (e.g., neuroticism, extraversion, openness, agreeableness, and conscientiousness) and QOL in the epileptic patients.

\section{Material and methods}

This cross-sectional study was conducted on all the patients with epilepsy, who were referred to Neurology Clinic of Ali-ibn Abi Talib Hospital in Zahedan, Iran in 2015. In total, 100 epileptic patients were employed in this study using convenience sampling method.

The inclusion criteria were as follows: 1 ) $\geq 18$ years of age, 2) epilepsy diagnosis by a neurologist, 3) an elapse of at least one year from the diagnosis, 4) providing informed consents, and 5) proficiency in reading and writing Farsi. The patients with the incidence of seizure during the past 24 hours and those with severe intellectual or cognitive problems were excluded from the study.

\section{Research tools}

The short form NEO Personality Inventory (NEO-PI) is an appropriate 60-item assessor to evaluate the main five personality characteristics including extraversion, agreeableness, conscientiousness, neuroticism, and openness to experience. The correlation between the five subscales of the long and short forms of the NEO was calculated by Costa et al., which ranged from 0.77-0.92. In addition, the internal consistency of the subscales of this questionnaire ranged from 0.68-0.86 [14]. In Iran, the long and short forms of the NEO were normed by Garousi et al. and Farnam et al., respectively $[15,16]$. The short Form Health Survey (SF-12) is a 12-item multipurpose survey, which is used to evaluate the QOL. Based on this questionnaire, the QOL in the patients was divided into three categories: appropriate, middle, and weak. The reliability and validity of this questionnaire were calculated by Montazeri et al., which were 0.72 and 0.73 , respectively. Furthermore, the correlation between the physical and mental health subscales of this questionnaire was high [3].

\section{Study design}

After enrolling the patients, the study program was explained to the participants and their informed consents were obtained. The patients who were unwilling to participate in the project were excluded from the study. Subsequently, the NEO-PI and SF-12 were filled in by all the subjects. The data were recorded and then entered into SPSS software version 18. Data analysis was performed using ANOVA, t-test, and Chi-square tests. P-valueless than 0.05 was considered statistically significant.

\section{Results}

According to the results of the study, $32 \%$ and $68 \%$ of the patients were male and female, respectively. The mean age of the patients was $26.89 \pm 6.26$ years (age range: $18-54$ years). The mean ages of the males and females were $25.56 \pm 4.94$ and $27.54 \pm 6.75$ years, respectively. Additionally, about $63 \%$ of the patients were married and $37 \%$ of them were single. Regarding the literacy level, about 55\% of the subjects had less than high school education and $45 \%$ of them had high school diploma or higher education.

The average duration of epilepsy was $6.42 \pm 4.16$ years, ranging from 1-20 years. About $23 \%$ of the patients had a history of psychiatric disorders and 13\%, 4\%, and $2 \%$ of them had cardiovascular diseases, hypertension, and diabetes, respectively. Furthermore, $8 \%$ of the participants had a history of cardiovascular diseases and psychiatric disorders, simultaneously.

As shown in the study, the mean QOL scores were 28.94 \pm 4.58 , ranging from 20-42. The study of QOL scores and other studied variables showed that there was no significant difference in the QOL between the two genders $(P=0.403)$. However, no significant relationship was found between the QOL scores and age $(P=0.816)$, epilepsy duration ( $P=0.240)$, literacy level $(P=0.425)$, and marital status $(P=0.965)$. As the results indicated, the QOL status was weak, middle, and appropriate in about $15 \%, 78 \%$, and $7 \%$ of the patients, respectively. The scores of five personality factors are illustrated in 
table 1. The study of correlation between the five personality factors and QOL demonstrated that the QOL was negatively correlated with openness to experience $(r=-0.283, P=0.007)$ and neuroticism $(r=-0.234$, $P=0.025)$. Furthermore, there was a significant positive correlation between conscientiousness $(r=0.223$, $P=0.036)$, agreeableness $(r=0.213, P=0.041)$, and extraversion ( $r=0.497, P>0.001)$. The mean of five personality traits in the patients based on the QOL is displayed in Table 2. In addition, diagram 1 displays the comparison between the mean QOL based on age and gender.

As shown in Table 3, ANOVA was used to evaluate the significance of the regression model. The residual sum of squares and sum of squares regression were 59.301 and 10.712, respectively. As the results indicated, the regression model was found to be significant $(F=5.536$, $\mathrm{P}<0.0005)$.
The prediction of the QOL based on personality factors showed that the extraversion and neuroticism are two significant predictors of the QOL. Moreover, the square of the correlation coefficient between the variables revealed that about $23 \%$ of the variance of the criterion variable (QOL) is predictable by the predictor variables.

\section{Discussion}

According to the findings of the present study, neuroticism and extraversion are two predictors of the QOL in epileptic patients. Regarding this, the QOL scores were significantly lower in the epileptic patients who had higher scores in neuroticism. Furthermore, the epileptic patients with higher scores in extraversion had higher QOL. Generally, the psychiatric and behavioral disorders are highly prevalent in patients with epilepsy. The personality disorders in these patients were estimated to range from $4-38 \%[17,18]$. In addition, about $31 \%$ of

Table1. Descriptive statistics of the personality characteristics

\begin{tabular}{|c|c|c|c|c|}
\hline & Mean & SD & Minimum & Maximum \\
\hline Conscientiousness & 29.52 & 6.59 & 17 & 44 \\
\hline Agreeableness & 27.34 & 4.54 & 16 & 38 \\
\hline Openness & 23.70 & 4.12 & 16 & 32 \\
\hline Extraversion & 25.94 & 4.84 & 16 & 38 \\
\hline Neuroticism & 25.67 & 5.04 & 15 & 37 \\
\hline
\end{tabular}

Table2. The mean of the personality characteristics based on the quality of life

\begin{tabular}{|c|c|c|c|c|c|c|}
\hline & \multicolumn{2}{|c|}{ Weak } & \multicolumn{2}{|c|}{ Middle } & \multicolumn{2}{|c|}{ Appropriate } \\
\hline & Mean & SD & Mean & SD & Mean & SD \\
\hline Conscientiousness & 29.15 & 6.26 & 29.25 & 6.61 & 3.83 & 6.24 \\
\hline Agreeableness & 27.64 & 3.24 & 27.08 & 4.65 & 30.4 & 5.63 \\
\hline Openness & 25.15 & 3.33 & 23.54 & 4.27 & 21.33 & 2.08 \\
\hline Extraversion & 23.5 & 3.39 & 26.09 & 4.85 & 31.5 & 4.5 \\
\hline Neuroticism & 29.35 & 5.52 & 24.8 & 4.61 & 27.5 & 5.5 \\
\hline
\end{tabular}

Table3. Simultaneous multiple regression analysis indices

\begin{tabular}{|c|c|c|c|c|c|}
\hline \multirow[t]{2}{*}{ Model } & \multicolumn{2}{|c|}{ Unstandardized coefficients } & \multicolumn{2}{|c|}{ Standardized coefficients } & \multirow[t]{2}{*}{ P-value } \\
\hline & $\mathbf{F}$ & SEm* & Beta & $\mathbf{t}$ & \\
\hline Fixed amount & 30.095 & 5.237 & - & 5.747 & $>0.0005$ \\
\hline Conscientiousness & -0.037 & 0.071 & -0.066 & -0.521 & 0.604 \\
\hline Agreeableness & 0.020 & 1.829 & 0.024 & 0.198 & 0.844 \\
\hline Openness & -0.153 & 0.110 & -0.169 & -1.383 & 0.171 \\
\hline Extraversion & 0.302 & 0.094 & 0.384 & 3.229 & 0.002 \\
\hline Neuroticism & -0.206 & 0.074 & -0.282 & -2.763 & 0.007 \\
\hline
\end{tabular}


the participants had a history of psychiatric disorders. Epilepsy, like a debilitating illness, leads to the reduction of self-efficacy, sense of control, as well as self-esteem and brings about some social problems $[19,20]$. Moreover, it can be associated with cognitive and behavioral changes [21]. The patients with epilepsy have dysfunctional attitudes, which affect their compatibility with the disease [22]. Furthermore, the QOL in the epileptic patients is affected by non-biological factors such as socio-cultural values [23]. Many studies have investigated the QOL in patients with epilepsy $[12,24]$.

In a study conducted by Djibuti et al. [25], age was identified as an effective factor in the QOL and cognitive function. However, in the current study, the QOL showed no significant relationship with gender and age, which was consistent with the findings of a similar study conducted by Tlusta et al. [26]. In addition, Swinkels et al. [27] showed that there was a significant relationship between the personality characteristics and such variables as age of seizure onset, epilepsy duration and frequency, and the number of anti-epileptic medicines. However, according to a study by Thompson et al., there was no significant relationship between the personality characteristics and the frequency and duration of epilepsy [28].

Afzalaghaee et al. [29] study demonstrated that age, gender, education level, type of epilepsy, and numbers of seizures were predictors of total QOL in the patients with epilepsy. They demonstrated that with the increase of the seizure episodes, the QOL scores were reduced in all four domains of this concept. In addition, they concluded that the number of seizures and female gender had higher effects on the QOL, compared to the other studied variables. Therefore, controlling the numbers of seizures is the main factor in improving the QOL in patients with epilepsy.

Since the epileptic patients may have problems in learning due to psychological and social consequences of the disease [30], it is expected that the patients with higher education have more attention to the mental health than the other patients. According to a study, the QOL scores were significantly lower in patients with lower education and social levels than those with higher education and social levels [31]. However, in our study, there was no significant difference between the frequency of epilepsy and different literacy levels, which may be due to the participants' different demographics.

Total score of QOL in the epileptic patients was higher in the studies carried out by Norsaadah et al. [12] and Chehrehgosha et al. [23] than that of the current study. This difference may be rooted in the use of different study designs and tools for the assessment of the QOL.
According to our study, the neuroticism was found to be a predictor of the QOL in the epileptic patients, i.e., the QOL scores were significantly lower in the epileptic patients who had high scores in neuroticism. Some evidence suggests that the low $\mathrm{QOL}$ is more associated with depression, anxiety, neuroticism, the frequency of seizures [32, 33]. Furthermore, major factors such as the feeling of isolation and social exclusion, poor academic performance, job limitations, and financial difficulties have a negative effect on the lifestyle of people with epilepsy, which can lead to the depression in these patients $[34,35]$. Moreover, cultural factors play an important role in the epileptic patients. According to Norsaadah et al. [12], the occurrence of seizures was the most important concern of these patients, which was known as the most important confounding factor for the QOL. However, in another study carried out by Viteva et al. [24] in Taiwan, job limitation was the most important confounder for this concept. As a result, the mentioned factors can lead to depression, anxiety, and neuroticism in epileptic patients.

As the findings of the current study demonstrated, extraversion was another predictor of the QOL. Similarly, the effect of extraversion on the improved QOL has been indicated in the literature $[11,36]$. However, the evidence denoting the impact of the personality factors on the QOL is limited.

Similar to our study, Testa et al. [37] reported a strong correlation between the current mood state of the patients and their QOL; however, the moderating role of the mood state was not significant with the incidence of chronic psychological symptoms. Furthermore, they observed a relationship between seizure diagnosis and health-related QOL.

The patients with epilepsy suffer from the unpredictability of future convulsions and are faced with stigma, which can be one of the most distressing consequences of seizure and is experienced by a quarter of the epileptic patients [38]. These factors can affect the QOL in epileptic patients [39]. Consequently, the assessment of QOL and its influential factors is critical.

\section{Conclusion}

This study demonstrated that the extraversion and neuroticism are two predictors of the QOL in the epileptic patients. Accordingly, patients with high levels of neuroticism reported low QOL, whereas those with high levels of extraversion reported high QOL.

\section{References:}

1. Pandey R, Gupta S, Tandon S, et al. Baccoside A suppresses epileptic-like seizure/convulsion in Caenorhabditis elegans. Seizure. 2010; 19(7): 439-442, doi: 10.1016/j.seizure.2010.06.005, indexed in Pubmed: 20598917 
2. Theodore WH, Spencer SS, Wiebe S, et al. Epilepsy in North America: a report prepared under the auspices of the global campaign against epilepsy, the International Bureau for Epilepsy, the International League Against Epilepsy, and the World Health Organization. Epilepsia. 2006; 47(10): 1700-1722, doi: 10.1111/j.1528 -1167.2006.00633.x, indexed in Pubmed: 17054693.

3. Montazeri A, Vahdaninia M, Mousavi SJ, et al. The Iranian version of 12-item Short Form Health Survey (SF-12): factor structure, internal consistency and construct validity. BMC Public Health. 2009; 9: 341, doi: 10.1186/1471-2458-9-341, indexed in Pubmed: 19758427.

4. Baker GA, Jacoby A, Gorry J, et al. SIGN Group. Quality of life of people with epilepsy in Iran, the Gulf, and Near East. Epilepsia. 2005; 46(1): 132-140, doi: 10.1111/j.0013-9580.2005.20704.x, indexed in Pubmed: 15660779.

5. Jolfaei AG, Nasr Es, MirblockJalali Z, et al. Assessment of personality disorders in epileptic patients referred to epilepsy clinic of RasoulAkram Hospital. Razi Journal of Medical Sciences. 2015; 21(129): 10-7.

6. Lloyd G, Guthrie E. Handbook of liaison psychiatry. Cambridge University Press 2007.

7. Solli O, Stavem K, Kristiansen IS. Health-related quality of life in diabetes: The associations of complications with EQ-5D scores. Health Qual Life Outcomes. 2010; 8: 18, doi: 10.1186/1477-7525-8-18, indexed in Pubmed: 20132542

8. Wen J, Yk S, Yp L, Yuan P, Wang F, Garcia O. Quality of Life. Physical Diseases, and Psychological Impairment among Survivors. 2012: 3.

9. Sabaz M, Cairns DR, Lawson JA, et al. The health-related quality of life of children with refractory epilepsy: a comparison of those with and without intellectual disability. Epilepsia. 2001; 42(5): 621-628, doi: 10.1046/j.1528-1157.2001.25200.x, indexed in Pubmed: 11380569.

10. van Straten A, Cuijpers P, van Zuuren FJ, et al. Personality traits and health-related quality of life in patients with mood and anxiety disorders. Qual Life Res. 2007; 16(1): 1-8, doi: 10.1007/s11136006-9124-x, indexed in Pubmed: 17033892

11. Aarstad HJ, Aarstad AKH, Birkhaug EJ, et al. The personality and quality of life in HNSCC patients following treatment. Eur J Cancer 2003; 39(13): 1852-1860, doi: 10.1016/s0959-8049(03)00308-3, indexed in Pubmed: 12932662

12. Norsaadah B, Zainab J, Knight A. The quality of life of people with epilepsy at a tertiary referral centre in Malaysia. Health Qual Life Outcomes. 2013; 11: 143, doi: 10.1186/1477-7525-11-143, indexed in Pubmed: 23972031

13. Hoare $P$, Mann H, Dunn S. Parental perception of the quality of life among children with epilepsy or diabetes with a new assessment questionnaire. Qual Life Res. 2000: 9(6): 637-644 doi: 10.1023/a:1008980608568, indexed in Pubmed: 11236854

14. Costa PT, McCrae RR. Cross-sectional studies of personality in a national sample: 1 . Development and validation of survey measures. Psychol Aging. 1986; 1(2): 140-143, doi: 10.1037//0882 7974.1.2.140, indexed in Pubmed: 3267390.

15. Garousi FM, Mehryar A, Ghazi TM. Application of the neop ir test and analytic evaluation of it. Journal of Humanities 2001; 11 (39): 173-198

16. Farnam A, Somi MH, Sarami F, et al. Personality factors and profiles in variants of irritable bowel syndrome. World J Gastroenterol. 2007; 13(47): 6414-6418, doi: 10.3748/wjg.v13.i47.6414, indexed in Pubmed: 18081232.

17. Barrash J, Tranel D, Anderson SW. Acquired personality disturbances associated with bilateral damage to the ventromedial prefrontal region. Dev Neuropsychol. 2000; 18(3): 355-381, doi: 10.1207/ S1532694205Barrash, indexed in Pubmed: 11385830.

18. Swinkels WAM, Duijsens IJ, Spinhoven Ph. Personality disorder traits in patients with epilepsy. Seizure. 2003; 12(8): 587-594, doi: 10.1016/s1059-1311(03)00098-0, indexed in Pubmed: 14630499

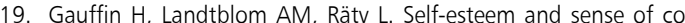
herence in young people with uncomplicated epilepsy: a 5-year follow-up. Epilepsy Behav. 2010; 17(4): 520-524, doi: 10.1016/j. yebeh.2010.01.167, indexed in Pubmed: 20227922.

20. Chen HF, Tsai YF, Lin YP, et al. The relationships among medicine symptom distress, self-efficacy, patient-provider relationship, and medication compliance in patients with epilepsy. Epilepsy Behav. 2010: 19(1): 43-49, doi: 10.1016/j.yebeh.2010.06.007, indexed in Pubmed: 20719572.
21. LaFrance WC, Miller IW, Ryan CE, et al. Cognitive behavioral therapy for psychogenic nonepileptic seizures. Epilepsy Behav. 2009; 14(4): 591-596, doi: 10.1016/j.yebeh.2009.02.016, indexed in Pubmed: 19233313

22. Kalantari M, Molavi $H$, Najafi MR, et al. Effectiveness of cognitive-behavioral group therapy with focusing on dysfunctional attitudes in epilepsy on quality of life in intractable epileptic patients. International Journal of Behavioral Sciences. 2011; 4(4): 255-260.

23. Chehrehgosha M, Seyyedolshohadayee M, Hosseini A. Quality of life and its related factors in adolescents with epilepsy. Iran Journal of Nursing. $2011 ; 24(73)$ : 47-54.

24. Viteva El, Viteva E. Impact of social factors on the quality of life of patients with refractory epilepsy. Acta Neurol Taiwan. 2013; 22(2): 51-58, indexed in Pubmed: 24030036

25. Djibuti M, Shakarishvili R. Influence of clinical, demographic, and socioeconomic variables on quality of life in patients with epilepsy: findings from Georgian study. J Neurol Neurosurg Psychiatry. 2003; 74(5): 570-573, doi: 10.1136/jnnp.74.5.570, indexed in Pubmed: 12700294.

26. Tlusta E, Zarubova J, Simko J, et al. Clinical and demographic characteristics predicting QOL in patients with epilepsy in the Czech Republic: how this can influence practice. Seizure. 2009; 18(2): 85-89, doi: 10.1016/j.seizure.2008.06.006, indexed in Pubmed: 18644739.

27. Swinkels WAM, van Emde Boas W, Kuyk J, et al. Interictal depression, anxiety, personality traits, and psychological dissociation in patients with temporal lobe epilepsy (TLE) and extra-TLE. Epilepsia. 2006; 47(12): 2092-2103, doi: 10.1111/j.1528-1167.2006.00808.x indexed in Pubmed: 17201709.

28. Thompson P, Batzel L, Wilkus R. Millon clinical multiaxial inventory assessments of patients manifesting either psychogenic or epileptic seizures. Journal of Epilepsy. 1992; 5(4): 226-230, doi: 10.1016/ s0896-6974(05)80121-5.

29. Afzalaghaee M, Dehghani M, Alimi R, et al. Predictors of Quality of Life in Patients with Epilepsy. journal of knowledge \& health. 2015; 10(1): 11.

30. Jacoby A, Buck D, Baker G, et al. Uptake and costs of care for epilepsy: findings from a U.K. regional study. Epilepsia. 1998; 39(7): 776-786, doi: 10.1111/j.1528-1157.1998.tb01164.x, indexed in Pubmed: 9670907

31. Mohammad MS, Hemeida S, Rabah AM. Health status and quality of life in epileptic children and adolescents. Egypt J Neurol Psychiat Neurosurg. 2010; 47: 83-92.

32. Loring DW, Meador KJ, Lee GP. Determinants of quality of life in epilepsy. Epilepsy Behav. 2004; 5(6): 976-980, doi: 10.1016/j. yebeh.2004.08.019, indexed in Pubmed: 15582847.

33. Lehrner J, Kalchmayr R, Serles W, et al. Health-related quality of life (HRQOL), activity of daily living (ADL) and depressive mood disorder in temporal lobe epilepsy patients. Seizure. 1999; 8(2): 88-92, doi: 10.1053/seiz.1999.0272, indexed in Pubmed: 10222299.

34. Jobe PC. Common pathogenic mechanisms between depression and epilepsy: an experimental perspective. Epilepsy Behav. 2003; 4 Suppl 3: S14-S24, doi: 10.1016/j.yebeh.2003.08.020, indexed in Pubmed: 14592636

35. Lach LM, Elliott I, Giecko T, et al. Patient-reported outcome of pediatric epilepsy surgery: social inclusion or exclusion as young adults? Epilepsia. 2010; 51(10): 2089-2097, doi: 10.1111/j.1528-1167.2010.02584.x indexed in Pubmed: 20477845.

36. Dubayova T, Krokavcova M, Nagyova I, et al. Neuroticism and extraversion in association with quality of life in patients with Parkinson's disease. Qual Life Res. 2009; 18(1): 33-42, doi: 10.1007/s11136008-9410-x, indexed in Pubmed: 18989757.

37. Testa SM, Schefft BK, Szaflarski JP, et al. Mood, personality, and health-related quality of life in epileptic and psychogenic seizure disorders. Epilepsia. 2007; 48(5): 973-982, doi: 10.1111/j.1528-1167.2006.00965.x, indexed in Pubmed: 17284298.

38. Bandstra NF, Camfield CS, Camfield PR. Stigma of epilepsy. Can J Neurol Sci. 2008; 35(4): 436-440, doi: 10.1017/s0317167100009082, indexed in Pubmed: 18973059.

39. MacLeod JS, Austin JK. Stigma in the lives of adolescents with epilepsy: a review of the literature. Epilepsy Behav. 2003; 4(2): 112-117, doi: 10.1016/s1525-5050(03)00007-6, indexed in Pubmed: 12697134 